\title{
A Cross Sectional Study on the Effect of Stress and Academic Stressors Among International Medical Students of a Romanian University
}

\author{
Cristina Hotoleanu, PhD, MD \\ Andrei Hotoleanu, Medical Student
}

Iuliu Hatieganu University of Medicine and Pharmacy, Romania

Doi:10.19044/esj.2021.v17n17p51

Submitted: 12 April 2021

Accepted: 11 May 2021

Published: 31 May 2021
Copyright 2021 Author(s)

Under Creative Commons BY-NC-ND

4.0 OPEN ACCESS

Cite As:

Hotoleanu C. \& Hotoleanu A. (2021). A Cross Sectional Study on the Effect of Stress and Academic Stressors Among International Medical Students of a Romanian University. European Scientific Journal, ESJ, 17(17), 51.https://doi.org/10.19044/esj.2021.v17n17p51

\begin{abstract}
Medical students are exposed to increased stress due to academic, psycho-social and health-related factors. This study aimed to assess the levels of stress and the associations with socio-demographic characteristics and academic performance; the frequency of the major academic stressors; the most stressful factors as stated by the students themselves. A cross-sectional study including 110 international medical students of the 3rd-year was performed in the first two weeks of November 2019. A questionnaire including socio-demographic data, a list with potential academic stressors and an open question regarding the greatest stressors in student's opinion as well as The Kessler Psychological Distress Scale, was administrated in pen-andpaper format. Mild, moderate and severe levels of stress were found in $36.73 \%, 22.44 \%$, and $13.26 \%$ of students, respectively. Increased levels of stress were associated with poor academic performance and did not correlate with age or country of origin. The frequency of moderate and severe stress was 3-times greater in women than in men. The most stressful factors in students' opinion were the academic stressors (88.77\%) followed by psychosocial factors $(25.51 \%)$ and health-related factors $(9.18 \%)$. The frequency of examination was perceived as a stressor always present by more than $25 \%$ of the students. Most of the students showed elevated levels of stress. Academic factors were the most important stressors in students' opinion.
\end{abstract}


Further research is needed to identify the proper strategy to rectify academicrelated problems to decrease the levels of stress.

Keywords: Students, medical; psychological stress; questionnaires

\section{Introduction}

Selye, considered to be the father of stress research, introduced the term stress in medicine to describe the "nonspecific response of the body to any demand". Although a minor level of stress is beneficial, high levels of stress have a negative impact on the physical health and psychosocial wellbeing.

Medical students face high levels of stress due to academic, psychosocial and health-related factors. The stress among medical students is greater compared to students from other specialties (Garg et al., 2017). Many factors contribute to this: an extensive medical curriculum, high workload, exposure to death and human suffering, high academic expectations and tough competition. Numerous studies from various countries reported the academic factors as the main stressors for medical students (Shah et al.,2010; Erschens et al., 2018; Rafique et al., 2019).

High levels of stress may lead to poor academic performance, depression, drug use, burnout and even suicide (Weber et al., 2019). A recent meta-analysis including studies from 47 countries has shown that more than $25 \%$ of medical students have depression and about $10 \%$ present suicidal ideation (Rotenstein et al., 2016). The severity of stress and depression experienced by female medical students appears to be greater in comparison to male students (Qamar et al., 2014; Hill et al., 2018).

A few previous studies conducted in Romania assessed the correlations between the stress and anxiety, depression and burnout in medical students (Iorga, Dondas, et al., 2018; Iorga, Muraru, et al., 2019; Popa-Velea et al., 2017). Although the association of the academic stress and personality profile has been studied by Bob et al. (2014), to the best of our knowledge, no other research in our country has been focused on the analysis of the academic factors, neither on the identification of the most important stressors in students' opinion.

This study has four main aims: 1) to assess the levels of stress; 2) to analyze the association of stress with socio-demographic characteristics (gender, age, country of origin) and academic performance (reflected by the average grade in the previous year); 3) to evaluate the frequency of the occurrence of the major academic stressors; 4) to detect the most stressful factors as stated by the students themselves. The identification of the stressors may contribute to the development of a proper strategy to reduce the negative effects of the stress. 


\section{Methods}

A cross-sectional study targeting all third-year English-language course medical students of our Medical Department of a Romanian University was performed in the first two weeks of November $2019(\mathrm{~N}=110)$. The Ethics Committee of the University approved the study (108/2019). The students were invited to participate via class announcement. They were informed the survey requires 10-15 minutes to complete and the participation is anonymous, voluntary and not compensated. The objectives of the study were explained. A questionnaire including general data (age, gender, country of origin and the average grade), a list with potential academic stressors, the English version of The Kessler Psychological Distress Scale (K10) instrument, and an open question regarding the greatest stressors in student's opinion, were administrated in pen-and-paper format. The potential academic stressors were listed from the previously published studies: frequency of examination, performance in examination, academic curriculum, dissatisfaction with class lectures, non-availability of learning materials, worries about becoming a doctor, lack of time for recreation, competition with peers and lack of special guidance from the faculty (Shah et al., 2010; Saipanish, 2003). Their frequency of occurrence was classified as: never, rarely, sometimes, often and always, with the corresponding scores on a Likert scale: 1, 2, 3, 4 and 5, respectively.

K10, widely used to assess the non-specific psychological distress, contains 10 items; each of these are scored from 1 to 5 and the scores are summed, generating a total score ranging from 10 to 50. Increased levels of stress, corresponding to a score $\geq 20$, are classified as: mild stress for scores between 20 and 24, moderate stress for scores between 25 and 29 and severe stress for scores between 30 and 50 (Kessler et al., 2002).

The most stressful factors stated by the students were further included in three categories: academic, psychosocial and health-related factors and their frequency was calculated.

According to the participants' country of origin, four subsamples were set up: 1) Central and Eastern European countries (Germany, Hungary, Poland, Romania); 2) European Mediterranean countries (Spain, Italy, Greece, France); 3) Israel; 4) other countries (USA, Canada, Tunisia, Morocco, Ireland, England, Jordan- each of these with $<2 \%$ students participating in this study).

Students who offered incomplete responses, declined the participation or were absent when the survey took place were excluded from the study.

Data were analyzed using Statistical Package for Social Sciences (SPSS) 17.0 for Windows (SPSS, Inc., Chicago, IL, USA). Descriptive analysis was used to calculate the frequency of variables. The two-tailed ttests were applied to compare means of continuous variables. Binary data were 
analyzed using the chi-square test. The associations between stress, gender, age and academic performance were expressed as odds ratios (OR) with a 95\% confidence interval (CI) at a significance level of $\mathrm{p}<0.05$. The comparison of K10 scores according to the country of origin was conducted using one-way ANOVA.

\section{Results}

Out of 110 students, 98 returned the completely filled questionnaires resulting in an overall response rate of $89.09 \%$. The mean age of the participants was 22.91 years old; the study included 52 female students with a mean age of 22.23 years and 46 male students with a mean age of 23.69 years. The socio-demographic profile of the students is shown in table 1 .

Table 1. The socio-demographic profile of the participants

\begin{tabular}{|l|l|}
\hline Sociodemographic parameter & $\mathrm{N}=(\%)$ \\
\hline Female students & $52(53.06 \%)$ \\
\hline Male students & $46(46.93 \%)$ \\
\hline Age $\leq 22$ & $45(45.91 \%)$ \\
\hline Age $>22$ & $53(54.08 \%)$ \\
\hline Central- Eastern Europe & $59(60.20 \%)$ \\
\hline Mediterranean European countries & $17(17.34 \%)$ \\
\hline Israel & $14(14.28 \%)$ \\
\hline Other countries & $8(8.16 \%)$ \\
\hline
\end{tabular}

$\mathrm{N}=$ absolute frequency

The mean K10 score of the participants was 23.31. Most of the students (72.44\%) presented increased levels of stress (K10 $\geq 20)$. Mild, moderate and severe levels of stress were found in $36.73 \%, 22.44 \%$ and $13.26 \%$ students, respectively.

Female students presented a mean K10 score significantly higher than male students, 24.98 versus $21.41, \mathrm{p}=0.009$. The frequency of moderate and severe stress was 3-times greater in women than in men: $\mathrm{OR}=3.33, \mathrm{p}=0.005$, 95\%CI: $1.3729-8.09$; the mild levels of stress were found predominantly in males than in females, $\mathrm{p}=0.026, \mathrm{OR}=2.448,95 \% \mathrm{CI}: 1.071-5.779$.

Students aged $>22$ years presented a higher mean K10 score than those aged $\leq 22$ (23.96, respective 22.53$)$ but not statistically significant, $\mathrm{p}=0.303$. No association between increased levels of stress and age was found $(\mathrm{p}=0.437$, $\mathrm{OR}=1.189,95 \%$ CI: $0.491-2.876$ ).

The mean K10 scores according to the country of origin were the following: $22.40 ; 23.64 ; 25.42 ; 25.5$, for Central-Eastern Europe, European Mediterranean countries, Israel and other countries, respectively, with no significant differences according to the one-way Anova test $(\mathrm{F}=1.086, \mathrm{p}=$ $0.358)$. The increased levels of stress were not associated with the students' country of origin $(\mathrm{F}=1.782, \mathrm{p}=0.158)$. 
The distribution of the levels of stress according to K10 score and socio-demographic factors is shown in table 2.

Table 2. The levels of stress according to socio-demographic factors

\begin{tabular}{|l|l|l|l|l|}
\hline Socio-demographic factor & $\begin{array}{l}\text { Normal } \\
\text { levels of } \\
\text { stress } \\
(\mathrm{K} 10<20) \\
\mathrm{N}=(\%)\end{array}$ & $\begin{array}{l}\text { Mild stress } \\
(\mathrm{K} 10: 20-24) \\
\mathrm{N}=(\%)\end{array}$ & $\begin{array}{l}\text { Moderate } \\
\text { stress } \\
(\mathrm{K} 10: 25-29) \\
\mathrm{N}=(\%)\end{array}$ & $\begin{array}{l}\text { Severe stress } \\
(\mathrm{K} 10: 30-50) \\
\mathrm{N}=(\%)\end{array}$ \\
\hline Female students & $13(13.26)$ & $14(14.28)$ & $14(14.28)$ & $11(11.22)$ \\
\hline Male students & $14(14.28)$ & $22(22.44)$ & $8(8.16)$ & $2(2.04)$ \\
\hline Age $\leq 22$ & $12(12.24)$ & $14(14.28)$ & $11(11.22)$ & $8(8.16)$ \\
\hline Age $>22$ & $16(16.32)$ & $23(23.46)$ & $11(11.22)$ & $3(3.06)$ \\
\hline Central- Eastern Europe & $18(18.36)$ & $23(23.46)$ & $12(12.24)$ & $6(6.12)$ \\
\hline Mediterranean European countries $)$ & $5(5.10)$ & $5(5.10)$ & $3(3.06)$ & $4(4.08)$ \\
\hline Israel & $4(4.08)$ & $5(5.10)$ & $2(2.04)$ & $3(3.06)$ \\
\hline Other countries & $0(0)$ & $3(3.06)$ & $5(5.10)$ & $0(0)$ \\
\hline
\end{tabular}

The mean grade of the students with mild, moderate and severe stress was, respectively: 7.625, 7.931, 7.73. The academic performance of the students with increased levels of stress was significantly lower compared to those with normal levels of stress (mean grade 7.762, respective 8.111), $\mathrm{p}=$ 0.0356 . The academic performance according to the levels of stress is shown in figure1.

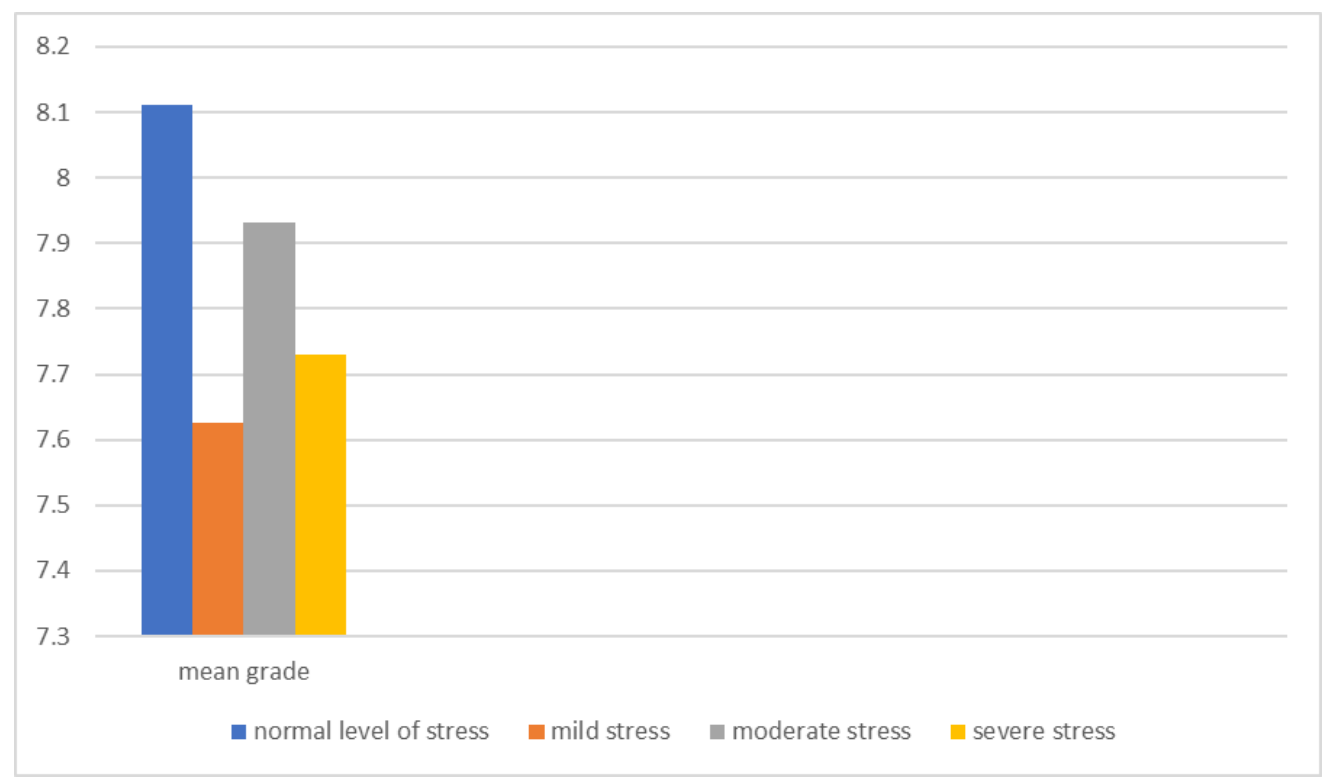

Figure1: the mean grade according to the levels of stress 
The academic stressors were predominantly perceived as occurring "sometimes", except the performance in examination (predominantly "often") and the competition with peers (predominantly "rare"). The academic factor reported as always present by more than $25 \%$ of the students was the frequency of examination. The frequency of the academic stressors perceived by the students is shown in table 3.

Table 3. The frequency of the occurrence of the academic stressors

\begin{tabular}{|c|c|c|c|c|c|}
\hline Academic stressor & $\begin{array}{l}\text { never } \\
\mathrm{N}=(\%)\end{array}$ & $\begin{array}{l}\text { rarely } \\
\backslash \mathrm{N}=(\%)\end{array}$ & $\begin{array}{l}\text { sometimes } \\
\mathrm{N}=(\%)\end{array}$ & $\begin{array}{l}\text { often } \\
\mathrm{N}=(\%)\end{array}$ & $\begin{array}{l}\text { always } \\
\mathrm{N}=(\%)\end{array}$ \\
\hline $\begin{array}{l}\text { frequency of } \\
\text { examination }\end{array}$ & $\begin{array}{r}1 \\
(1.02)\end{array}$ & $\begin{array}{r}8 \\
(8.16)\end{array}$ & $\begin{array}{r}33 \\
(33.67)\end{array}$ & $\begin{array}{r}30 \\
(30.61)\end{array}$ & $\begin{array}{r}26 \\
(26.53)\end{array}$ \\
\hline $\begin{array}{l}\text { performance in } \\
\text { examination }\end{array}$ & $\begin{array}{r}3 \\
(3.06)\end{array}$ & $\begin{array}{r}17 \\
(17.34)\end{array}$ & $\begin{array}{r}25 \\
(25.51)\end{array}$ & $\begin{array}{r}36 \\
(36.73)\end{array}$ & $\begin{array}{r}17 \\
(17.34)\end{array}$ \\
\hline academic curriculum & $\begin{array}{r}3 \\
(3.06)\end{array}$ & $\begin{array}{r}19 \\
(19.38)\end{array}$ & $\begin{array}{r}41 \\
(41.83)\end{array}$ & $\begin{array}{r}21 \\
(21.42)\end{array}$ & $\begin{array}{r}14 \\
(14.28)\end{array}$ \\
\hline $\begin{array}{l}\text { dissatisfaction with class } \\
\text { lectures }\end{array}$ & $\begin{array}{r}4 \\
(4.08)\end{array}$ & $\begin{array}{r}21 \\
(21,42)\end{array}$ & $\begin{array}{r}41 \\
(41.83)\end{array}$ & $\begin{array}{r}23 \\
(23.46)\end{array}$ & $\begin{array}{r}9 \\
(9.18)\end{array}$ \\
\hline $\begin{array}{l}\text { non-availability of } \\
\text { learning materials }\end{array}$ & $\begin{array}{r}7 \\
(7.14)\end{array}$ & $\begin{array}{r}27 \\
(27.55)\end{array}$ & $\begin{array}{r}32 \\
(32.65)\end{array}$ & $\begin{array}{r}26 \\
(26.53)\end{array}$ & $\begin{array}{r}6 \\
(6.12)\end{array}$ \\
\hline $\begin{array}{l}\text { worries about becoming } \\
\text { a doctor }\end{array}$ & $\begin{array}{r}18 \\
(18.36)\end{array}$ & $\begin{array}{r}22 \\
(22.44)\end{array}$ & $\begin{array}{r}40 \\
(40.81)\end{array}$ & $\begin{array}{r}13 \\
(13.26)\end{array}$ & $\begin{array}{r}5 \\
(5.10)\end{array}$ \\
\hline $\begin{array}{l}\text { lack of time for } \\
\text { recreation }\end{array}$ & $\begin{array}{r}6 \\
(6.12)\end{array}$ & $\begin{array}{r}18 \\
(18.36)\end{array}$ & $\begin{array}{r}31 \\
(31.63)\end{array}$ & $\begin{array}{r}30 \\
(30.61)\end{array}$ & $\begin{array}{r}13 \\
(13.26)\end{array}$ \\
\hline competition with peers & $\begin{array}{r}28 \\
(28.57)\end{array}$ & $\begin{array}{r}39 \\
(39.79)\end{array}$ & $\begin{array}{r}18 \\
(18.36)\end{array}$ & $\begin{array}{r}9 \\
(9.18)\end{array}$ & $\begin{array}{r}4 \\
(4.08)\end{array}$ \\
\hline $\begin{array}{l}\text { lack of special guidance } \\
\text { from the faculty }\end{array}$ & $\begin{array}{r}11 \\
(11.22)\end{array}$ & $\begin{array}{r}31 \\
(31.63)\end{array}$ & $\begin{array}{r}34 \\
(34.69)\end{array}$ & $\begin{array}{r}14 \\
(14.28)\end{array}$ & $\begin{array}{r}8 \\
(8.16)\end{array}$ \\
\hline
\end{tabular}

$\mathrm{N}=$ absolute frequency

The most stressful factors in students' opinion were the academic stressors $(88.77 \%)$ followed by psychosocial factors $(25.51 \%)$ and healthrelated factors $(9.18 \%)$ as shown in figure2. 


\section{frequency of the most stressful factors}

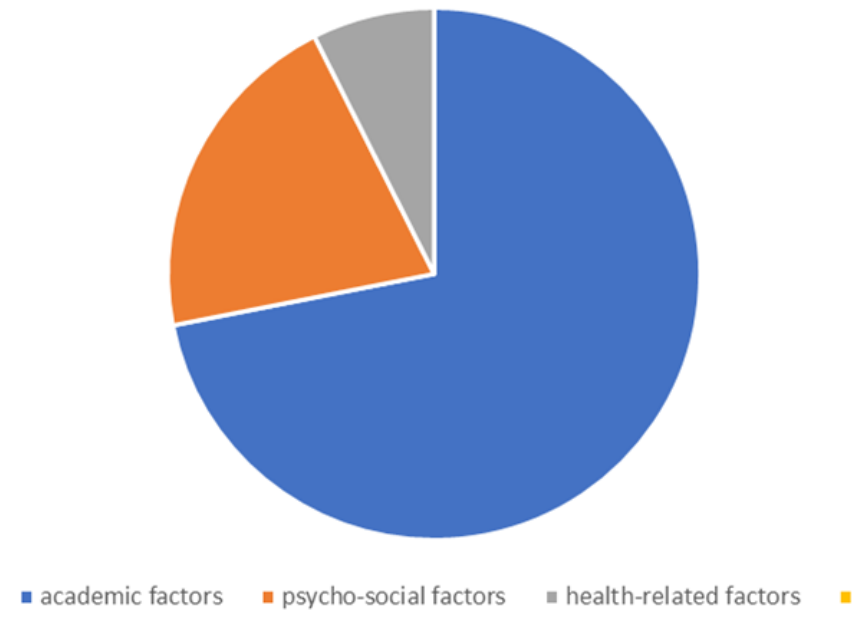

Figure 2: the frequency of the most stressful factors

The academic stressors were identified alone as the most stressful factors by $67.34 \%$ of students and together with other factors in $21.42 \%$ of cases. All the academic stressors described by the students were found in the previous list and, furthermore, two other factors were noted: the mandatory attendance at the practical classes $(6.12 \%)$ and the communication with teaching staff $(3.06 \%)$. The most stressful psychosocial factors were the following: financial issues (8.16\%), accommodation away from home and living conditions (7.14\%), family-related factors (5.1\%) and social interactions $(5.1 \%)$. The problems regarding nutrition/weight and sleep were identified as the most stressful health-related factors $(5.1 \%, 4.08 \%$ of cases, respectively).

\section{Discussion}

This study showed increased levels of stress in about $70 \%$ of the students, with an overall K10 score corresponding to mild stress; severe stress occurred in $13 \%$ of cases. The prevalence of stress among medical students varies largely, from $12.2 \%$ to $96.7 \%$, according to a meta-analysis including 29 studies from Europe and the English-speaking world outside North America (Hope \& Henderson, 2014). This may be explained by different design of the studies and the instruments used to assess stress. Other studies using the same instrument, K10, found the following frequency of stress among medical students: $67.9 \%, 41.7 \%, 77.5 \%, 52 \%$; severe stress occurred in: $21.8 \%, 24.26 \%, 30.2 \%, 33.8 \%$ of cases, respectively (Rafique et al., 2019; Qamar et al., 2014; Shawi et al., 2018; Saeed et al., 2016). Lower levels of 
severe stress were found in this study possibly explained by the enrolment of only the third-year students, final-year and first-year students presenting higher levels of stress according to some data (Iorga, Dondas, et al., 2018; Rafique et al., 2019; Shawi et al., 2018).

Previous studies in Romania, using different instruments to assess stress, reported high rates of stress, depression and anxiety among medical students and showed the association of stress with burnout, and, respective, a negative correlation with well-being (Popa-Velea et al., 2017; Bob et al., 2014; Iorga, Muraru et al., 2019; Costescu et al., 2018). This study did not assess these correlations, which may represent a limitation.

Female students presented higher levels of stress than males in this study, similar with most of the studies, which could be explained by specific psychosocial and behavioral profiles, with women willing to provide more information about psychological conditions than men (Erschens et al., 2018; Qamar et al., 2014; Hill et al., 2018; Kumar et al., 2019; Seedhom et al., 2019).

No association between stress and age was found in this study, in line with other data (Shah et al., 2010; Iorga, Dondas et al., 2018; McKerrow et al., 2020). However, some studies found increased levels of stress in older students, associated with financial problems and lack of social integration whereas others reported highest stress in younger students who require time to develop coping strategies (Kotter et al., 2017; Wahed \& Hassan, 2017; Rafique et al., 2019; Saeed et al., 2016). A prospective design of this study could have offered more data regarding the dynamic of stress in correlation with age.

This study showed the association of stress with poor academic performance, reflected by a significant lower mean grade of the students with increased levels of stress in comparison to those with normal levels of stress; this is in line with other studies (Iorga, Dondas et al., 2018; Sohail, 2013; Frazier et al., 2019). This association may be mediated by the effects of cortisol in the prefrontal cortex, promoting the impairment of the cognitive functions and by catecholamines which enhance the effect of stress; it has been shown that stress induces time-dependent changes of the memory stages (Vogel \& Schwabe, 2016). Sohail (2013) reported that the number of stressors correlated stronger with the academic performance than the level of stress. Stress leads to a decreased academic performance which increases the levels of stress, creating a vicious circle (Kotter et al., 2017).

No correlation between stress and the country of origin was found in this study, suggesting that stress may transcend the socio-cultural and geographical factors.

Studies that investigated the sources of stress reported the main role played by the academic stressors (Shah et al., 2010; Erschens et al., 2018; Kumar et al., 2019; Seedhom et al., 2019). This study showed that $88 \%$ of the 
students considered academic factors as the most important stressors. The frequency of examination was "always" perceived as a stressor by more than $25 \%$ of the students. The performance in examination was "often" seen as a stressful factor by most of the students. These findings point out to the need to reframe the examination patterns to decrease the negative impact of the academic stressors. Other studies, including qualitative literature, identified the exams (the performance pressure, preparing for examinations) as the most important stressors (Shah et al., 2010; Erschens et al., 2018; Weber et al., 2019). This study showed that the competition with peers was rarely perceived as a stressor; Hill at et al. (2018) reported different frequency of this factor according to the year of study, the highest frequency being found among the second-year students.

This study showed that academic stress factors occurred only in $21 \%$ of cases associated with psycho-social and/or health-related factors, suggesting the vulnerability to a specific category of stressors. This is in contrast with data reported by Shah et al. (2010) showing that students with academic stress were more likely to have psychosocial stressors or vice versa. Specific environment, including recreational facilities provided by the universities, may explain the differences.

This study showed that students perceived financial problems, living conditions, family-related factors (parental pressure and expectations) and limited time for social interactions as the most important psychosocial stressors, in line with other studies (Garg et al., 2017; Shah et al., 2010; Kumar et al., 2019). In this study, less than $10 \%$ of the students stated that healthrelated factors were the most important stressors for them. The detailed analysis of psychosocial and health-related factors on a Likert scale was not performed in this study, the focus being on the academic factors. Rafique et al. (2019) reported that a physical medical problem is an independent risk factor for high perceived stress. In this study, obesity and poor sleep quality were identified as the most stressful health related factors, in line with other data (Wahed \& Hassan, 2017; Safhi et al., 2020).

The main limitations of this study include: the participation of only the 3rd-year international medical students of a public university, no analysis of the associations with depression and anxiety and the cross-sectional design. Non-response is a particular problem affecting cross-sectional studies and can result in bias, but the overall response rate in this study was high (89.09\%).

The strength of this study is mainly represented by the detection of the main sources of stress in students' opinion with implications for medical education. The identification of the academic factors as the most important stressors, especially the frequency and the performance in exams, suggests the need to improve the strategy of examinations. Medical students participating in self-development groups or utilizing multiple self-care practices (including 
nutrition, health responsibility, physical activity, spiritual growth) may present a greater resilience and a decrease in levels of stress (Holm et al., 2010; Ayala et al., 2018). Further research is needed to identify the best interventions, including stress management education focusing on coping strategies, student counseling and support groups.

\section{Conclusion}

Most of the students showed mildly elevated levels of stress. Female students presented higher levels of stress than males. Stress had a negative impact on academic performance. No significant association of stress with age and country of origin was found. Academic factors were the most important stressors in students' opinion, especially the frequency and the performance in exams. Further research is needed to identify the proper strategy to rectify academic-related problems to decrease the levels of stress.

\section{References:}

1. Ayala, E. E., Winseman, J. S., Johnsen, R. D., \& Mason, H. R. C. (2018). U.S. medical students who engage in self-care report less stress and higher quality of life. BMC Medical Education, 18(1):189. https://doi.org/10.1186/s12909-018-1296-x

2. Bob, M. H., Popescu, C. A, Pirlog, R., \& Buzoianu, A. D. (2014). Personality factors associated with academic stress in first year medical students. HVM Bioflux, 6(1), 40-44

3. Costescu, C., Oprea A., Herta D. C, \& Nemes B. (2018). Perceived stress and well-being among international first year medical students in Romania. Psihiatru.ro, 52(1), 23-26

4. Erschens, R., Herrmann-Wernern, A., Keifenheim, K. E., Loda, T., Bugaj, T. J., Nikendei, C., Lammerding-Koppel, M., Zipfel, S., \& Junne, F. (2018). Differential determination of perceived stress in medical students and high-school graduates due to private and training-related stressors. PLoS ONE, 13(1). Article e0191831. https://doi.org/10.1371/journal.pone.0191831

5. Frazier, P. A., Gabriel, A., Merians, A., \& Lust, K. (2019). Stress as an impediment to academic performance. Journal of American College Health, 67(6), 562-570. https://doi.org/10.1080/07448481.2018.1499649

6. Garg, K., Agarwal, M., \& Dalal, P. K. (2017). Stress among medical students: A cross-sectional study from a North Indian Medical University. Indian Journal of Psychiatry, 59(4), 502-504. https://www.indianjpsychiatry.org/text.asp?2017/59/4/502/223476 
7. Hill, M. R., Goicochea, S., \& Merlo, L. J. (2018). In their own words: stressors facing medical students in the millennial generation. Medical Education Online, 23(1):1530558.

https://www.ncbi.nlm.nih.gov/pmc/articles/PMC6179084/

8. Holm, M., Tyssen, R., Stordal, K. I., \& Haver, B. (2010). Selfdevelopment groups reduce medical school stress: a controlled intervention study. BMC Medical Education, 23(10). https://bmcmededuc.biomedcentral.com/articles/10.1186/1472-6920$10-23$

9. Hope, V., \& Henderson, M. (2014). Medical student depression, anxiety and distress outside North America: a systematic review. Medical Education, 48(10), 963-979. doi: 10.1111/medu.12512.

10. Iorga, M., Dondas. C., \& Zugun-Eloae, C. (2018). Depressed as freshmen, stressed as seniors: the relationship between depression, perceived stress and academic results among medical students. Behavioral Sciences, 8(8). https://www.mdpi.com/2076328X/8/8/70/htm

11. Iorga, M., Muraru, I. D., Munteanu, C., \& Petrariu, F. D. (2019). Depression, anxiety and stress among medical students. The MedicalSurgical Journal, 123(3): 496-505

12. Kessler, R. C., Andrews, G., Colpe, L. J., Hiripi, E., Mroczek, D. K., Normand, S. L., Walters, E. E., \& Zaslavsky, A. M. (2002). Short screening scales to monitor population prevalences and trends in nonspecific psychological distress. Psychological Medicine, 32, 959-976.

13. Kotter, T., Wagner, J., Brüheim, L., \& Voltmer, E. (2017). Perceived Medical School stress of undergraduate medical students predicts academic performance: an observational study. BMC Medical Education, 17(1), 256.

https://www.ncbi.nlm.nih.gov/pmc/articles/PMC5732510/

14. Kumar, B., Shah, M., Kumari, R., Kumar, A., Kumar J., \& Tahir, A. (2019). Depression, Anxiety, and Stress Among Final-year Medical Students. Cureus,11(3). https://www.cureus.com/articles/18501depression-anxiety-and-stress-among-final-year-medical-students

15. McKerrow, I., Carney, P. A., Caretta-Weyer, H., Furnari, M, \& Miller Juve, A. (2020). Trends in medical students' stress, physical, and emotional health throughout training. Medical Education Online, 25(1), 1709278. doi:10.1080/10872981.2019.1709278

16. Popa-Velea, O., Diaconescu, L., Mihailescu, A., Jidveian Popescu, M., \& Macarie G. (2017). Burnout and Its Relationships with Alexithymia, Stress, and Social Support among Romanian Medical Students: A Cross-Sectional Study. International Journal of Environmental 
Research and Public Health, 14(6), 560. https://doi.org/10.3390/ijerph14060560

17. Qamar, K., Kiani, M. R., Ayyub, A., Khan, A. A., \& Osama, M. (2014). Higher stress scores for female medical students measured by the Kessler Psychological Distress Scale (K10) in Pakistan. Journal of educational evaluation for health professions, 11(27). https://doi.org/10.3352/jeehp.2014.11.27

18. Rafique, N., Al-Asoom, L. I., Latif, R., Al Sunni, A., \& Wasi, S. (2019). Comparing levels of psychological stress and its inducing factors among medical students. Journal of Taibah University Medical Sciences, 14(6), 488-494. doi: 10.1016/j.jtumed.2019.11.002

19. Rotenstein, L. S., Ramos, M. A., \& Torre, M. (2016). Prevalence of depression, depressive symptoms, and suicidal ideation among medical students. A systematic review and meta-analysis. Journal of the American Medical Association, 316(21), 2214-2236. doi: 10.1001/jama.2016.17324.

20. Saeed, A. A., Bahnassy, A. A., Al-Hamdan, N. A., Almudhaibery, F. S, \& Alyahya, A. Z. (2016). Perceived stress and associated factors among medical students. Journal of Family and Community Medicine, 23,166-171 doi:10.4103/2230-8229.189132

21. Safhi, M. A, Alafif, R. A, Alamoudi, N. M, Alamoudi, M. M, Alghamdi, W. A, Albishri, S. F., \& Rizk, H. (2020). The association of stress with sleep quality among medical students at King Abdulaziz University. Journal of Family Medicine and Primary Care, 9, 1662-7

22. Saipanish R. (2003). Stress among medical students in a Thai medical school. Medical Teacher, 25, 5, 502-506 doi: 10.1080/0142159031000136716

23. Seedhom, A. E., Kamel, E. G., Mohammed, E. S., \& Raouf, N. R. (2019). Predictors of Perceived Stress among Medical and Nonmedical College Students, Minia, Egypt. International Jornal of Preventive Medicine, 10, 107.

https://www.ncbi.nlm.nih.gov/pmc/articles/PMC6592112/

24. Shah, M., Hasan S., Malik, S. \& Sreeramareddy, C.T. (2010). Perceived Stress, Sources and Severity of Stress among medical undergraduates in a Pakistani Medical School. BMC Medical Education.10(2).

https://bmcmededuc.biomedcentral.com/articles/10.1186/1472-6920$10-2$

25. Shawi, A., Abdullateef, A. N., Khedher, M. A., Rejab, M. S., \& Khaleel, R. N. (2018). Assessing stress among medical students in Anbar governorate, Iraq: a cross-sectional study. The Pan African Medical Journal, 31, 96. 
https://doi.org/10.11604/pamj.2018.31.96.16737

26. Sohail N. (2013). Stress and academic performance among medical students. Journal of the College of Physicians and Surgeons Pakistan, $23,67-71$.

27. Vogel, S., \& Schwabe, L. (2016). Learning and memory under stress: implications for the classroom. npj Science of Learning, 1, 16011. https://www.nature.com/articles/npjscilearn201611

28. Wahed, W. Y. A., \& Hassan, S. K. (2017). Prevalence and associated factors of stress, anxiety and depression among medical Fayoum University students. Alexandria Journal of Medicine, 53(1), 77-84

29. Weber, J., Skodda, S., Muth, T., Angerer, P., \& Loerbroks, A. (2019). Stressors and resources related to academic studies and improvements suggested by medical students: a qualitative study. BMC Medical Education, 19(312). https://doi.org/10.1186/s12909-019-1747-z 